\title{
Optimal behavior of responsive residential demand considering hybrid phase change materials
}

\author{
M. Shafie-khah a,b, M. Kheradmand ${ }^{\text {a,c }}$, S. Javadi a , M. Azenha ${ }^{\text {d }}$, J.L.B. de Aguiar ${ }^{c}$, J. Castro-Gomes $^{\mathrm{e}}$, \\ P. Siano ${ }^{\mathrm{b}}$, J.P.S. Catalão ${ }^{\mathrm{a}, \mathrm{f}, \mathrm{g}, *}$ \\ ${ }^{a}$ University of Beira Interior, R. Fonte do Lameiro, 6201-001 Covilhã, Portugal \\ ${ }^{\mathrm{b}}$ University of Salerno, Via Giovanni Paolo II, 132, Fisciano (SA) 84084, Salerno, Italy \\ ' CTAC, University of Minho, Azurém Campus, 4800-058 Guimarães, Portugal \\ d ISISE, University of Minho, Azurém Campus, 4800-058 Guimarães, Portugal \\ ${ }^{\text {e }}$ C-MADE, University of Beira Interior, 6201-001 Covilhã, Portugal \\ ${ }^{\mathrm{f}}$ Faculty of Engineering of the University of Porto, R. Dr. Roberto Frias, 4200-465 Porto, Portugal \\ ${ }^{\mathrm{g}}$ INESC-ID, Inst. Super. Tecn., University of Lisbon, Av. Rovisco Pais, 1, 1049-001 Lisbon, Portugal
}

\section{H I G H L I G H T S}

- An operational model of HEM system incorporating with a hybrid PCM is proposed in this paper.

- Incorporation of hybrid PCM mortar had a complementary effect on the proposed HEM system.

- The proposed model ensures the technical and economic limits of batteries and electrical appliances.

- The customer's electricity cost can be reduced up to $48 \%$ by utilizing the proposed model.

\section{A R T I C L E I N F O}

Article history:

Received 8 August 2015

Received in revised form 3 November 2015

Accepted 4 November 2015

Available online 18 November 2015

\section{Keywords:}

Buildings

Demand response programs

Household energy management

Phase change material

Thermal energy storage

\begin{abstract}
A B S T R A C T
Due to communication and technology developments, residential consumers are enabled to participate in Demand Response Programs (DRPs), control their consumption and decrease their cost by using Household Energy Management (HEM) systems. On the other hand, capability of energy storage systems to improve the energy efficiency causes that employing Phase Change Materials (PCM) as thermal storage systems to be widely addressed in the building applications. In this paper, an operational model of HEM system considering the incorporation of more than one type of PCM in plastering mortars (hybrid PCM) is proposed not only to minimize the customer's cost in different DRPs but also to guaranty the habitants' satisfaction. Moreover, the proposed model ensures the technical and economic limits of batteries and electrical appliances. Different case studies indicate that implementation of hybrid PCM in the buildings can meaningfully affect the operational pattern of HEM systems in different DRPs. The results reveal that the customer's electricity cost can be reduced up to $48 \%$ by utilizing the proposed model.
\end{abstract}

(c) 2015 Elsevier Ltd. All rights reserved.

\section{Introduction}

\subsection{Motivation}

According to the concept of effective deregulation of mature electric industry, smart grid issue has attracted a major attention with the vast investments in all over the world. Smart grid is the idea to improve the efficiency of power system from the generation

* Corresponding author at: University of Beira Interior, R. Fonte do Lameiro, 6201-001 Covilhã, Portugal. Tel.: +351 275 329914; fax: +351 275329972.

E-mail address: catalao@ubi.pt (J.P.S. Catalão). to end-user sides, that enables the consumers' participation [1]. Associated with the increase of the importance of smart grid concept, smart households, which can observe their usage and act to mitigate their electricity costs, have provided the ground to enable demand side activities [2]. Demand Response Programs (DRPs) are the key elements of the future smart grid to prepare the demand side activities [3]. DRPs generally concentrate on shifting the consumption of customers from peak to off-peak periods to reduce the pressure on utility-handled equipment, e.g. distribution transformers, lines, etc., and may provide a valuable resource for effective operation of smart grid structure [4]. Since a large part of the energy consumption in buildings is related to heating and cooling 


\section{Nomenclature}

\section{Superscripts}

Acc acceptable by the owner

App appliances

$B \quad$ batteries

$B 2 G$ batteries to the grid

$\mathrm{B2H}$ batteries to the household

ch charge

Cntrl controllable load

Crit critical load

Degr equipment degradation

dis discharge

ini initial value

G grid

$\mathrm{G} 2 \mathrm{H}$ grid to the household

$H$ household

$H 2 G \quad$ household to the grid

$H 2 B$ household to the batteries

Nom nominated amount of appliance consumption

Req required amount of appliance consumption

\section{Indices (sets)}

$i \quad$ controllable appliance

$t(T) \quad$ time

Operators

$\Delta \quad$ change in variable amount
Parameters and variables

B customer's benefit function

Cap battery capacity

$\operatorname{Cost}_{B} \quad$ capital cost of batteries

$C_{d} \quad$ cost of equipment degradation

$d \quad$ demand

Inc rate of incentive resulted from reducing the demand

$L_{E T} \quad$ battery lifetime

$P \quad$ power

Pen rate of penalty resulted from not reducing the demand

$r \quad$ charging/discharging rate of batteries

Rev customer's revenue function

SOC state of the charge

$s \quad$ binary variable that indicates ON/OFF state of a controllable appliance

$v \quad$ inelasticity parameter of demand

$V$ dissatisfaction of customer due to get distance from the reference demand

WP $\quad$ working period of a controllable appliance

$\eta \quad$ charge and discharge efficiencies

$\pi \quad$ scenario probability

$\lambda \quad$ price/tariff

$\varsigma$ incentive function

$\xi \quad$ penalty function

$\chi, \gamma \quad$ binary variables of receiving or injecting energy requirements, a thermal system is required to maintain the desirable interior temperature with the minimum energy consumption [5]. To this end, employment of thermal energy storage systems has a significant role in the energy consumption of future buildings [6]. In addition, the household electricity consumption should follow the DRPs by means of shifting and shaving the electricity load to reduce the electricity costs in a way that the level of comfort and satisfaction of the habitants are met [7].

\subsection{Literature review and background}

The effect of Demand Response (DR) on the load shape has been investigated by some economic models of price responsive loads in [8]. In addition, there are a large number of studies in context of DR strategies for smart households. In [2,9], an optimization approach has been presented for effective operation of a household considering a price signal based DR. In [10,11], an HEM has been presented using DR strategies to limit the peak power for the smart household. In [3], impacts of Electric Vehicle (EV) and DR on the distribution transformer loading have been reported and a DR strategy has been addressed as a load-shaping tool to mitigate the disadvantages of Plug-in Electric Vehicles (PEVs) on load peaks. In [12], a decision-support algorithm is presented for a HEM system. The decision-support algorithm optimizes energy services provision by enabling end users to assign values to desired energy services, and then scheduling their Distributed Energy Resources (DERs) to maximize net benefits. In [13], an optimal utilization of electrical appliances, PEVs and renewable energy resources is studied to reduce the customers electricity bill. In [14], an algorithm for HEM system is reported based on the measurement of the power consumptions of home appliances with respect to the time. On this basis, the power consumption patterns of each appliance are mea- sured and a real time-varying electricity price and the solar power generation profile are employed in a mathematical model. In $[15,16]$, a model to modify load patterns is reported by employing a time scheduling consumers. In the model of each household presented in [15], daily energy requirements and consumer preferences are considered and its impact of peak shaving and electricity cost is studied. In [17], an optimization method is presented to schedule interruptible loads. Based on this, total curtailments that the system requires in each hour are optimized considering the operational constraints of the available interruptible loads, minimizing the payment of customers and minimizing the frequency of interruptions.

In [18], an optimization model is addressed to adjust the hourly demand of a consumer in response to hourly electricity prices, considering the uncertainty of electricity price. In [19], a stochastic optimization of HEM system based on a hierarchical multitimescale approach is presented to schedule different characterizations of loads. In [20], stochastic and robust optimization approaches have been utilized to manage the residential appliances considering the uncertainties of electricity price. Furthermore, in [21], another DR strategy has been studied based on the estimation of the customer response to DRPs. In spite of a lot of research in the literature, impacts of both incentive-based and price-based DRPs as well as habitants' satisfaction on the behavior of HEM systems have been rarely addressed.

Many methodologies have been applied in order to improve the thermal energy saving systems in buildings [22,23], such as Phase Change Materials (PCM) that plays an important role in the future of buildings; because it is relatively easy to incorporate into building components [24]. The operation of the PCMs in the building application can be explained by: when the ambient temperature is increased, the PCM absorbs heat by melting. On the contrary, 
when the ambient temperature is decreased lower than the melting temperature of PCM, the PCM solidifies with energy release. On this basis, thermal exchanges between outside and inside can be reduced [25]. This leads to better leveled indoor temperatures, that tends to be in the vicinity of the PCM's melting point. Moreover, it has an interesting feature of shifting the building heating/cooling load from peak to off-peak electricity consumption periods [26].

According to the aforementioned features of PCM, several research studies have been addressed the incorporation of PCM into construction materials as a thermal energy storage system $[5,25]$. Several studies can be found in the literature regarding the energy savings that can be obtained through applications of PCM systems in buildings. Zhang et al. [27] have performed experiments in two test rooms with PCM and concluded that the daily cooling load can be reduced by $10.8 \%$ when $20 \%$ PCM is incorporated in the frame wall application. Chen et al. [28] investigated a test room with interior walls, ceiling and floor consisting of PCM layers as wallboard in Beijing (China) and the results shown energy saving of the heating season reached $10 \%$. Diaconu et al. [29] studied a new type of three-layer composite wall system incorporating PCM through numerical simulation, under consideration of the climatic conditions of Bechar (Algeria). They concluded that, the annual energy savings for space heating and cooling are respectively around $12.8 \%$ and $1.0 \%$. Chan [30] has performed a numerical study of a typical residential flat with PCM integrated in some of its external walls. He found that an annual energy saving of $2.9 \%$ in air-conditioning system could be achieved. However, the possibility of implementing more than one types of PCM (i.e. hybrid PCM) has been solely assessed through material level investigation [31,32]. Nevertheless, capability of the hybrid PCM to improve the performance of the PCM system in real scale building application has not been reported.

Although some work in the literature has studied the HEM systems, operational behavior of these responsive demands in the buildings with hybrid PCM incorporated into the plastering mortars has not been addressed.

\subsection{Aims and contributions}

Since the use of the hybrid PCM can keep the temperature of the buildings in more limited bounds, the energy consumption changes during the hours of the day. This means that the profile of electricity consumption changes. Therefore, the operational behavior of HEM systems is meaningfully different with the traditional buildings. This paper aims to find the optimal performance of HEM systems considering the satisfaction of customers in using different electrical appliances accounting hybrid PCM in plastering mortar in buildings.

According to the mentioned expression, the contributions of this paper can be summarized as below:

- Optimization of the household energy management systems in the buildings with hybrid PCM mortars.

- Modeling the participation of the household in both incentivebased and price-based DRPs considering the customers satisfaction.

- Modeling the effect of using hybrid PCM on the operation of energy storage systems considering different types of DRPs.

\subsection{Paper organization}

Section 2 describes the proposed hybrid PCM. In Section 3, the models of DRPs are explained. Section 4 is designated to mathematically formulation of the proposed model of the HEM system. Section 5 devotes the numerical results and Section 6 concludes the paper.

\section{Hybrid phase change material mortar: a case study of a simulated building}

\subsection{General considerations}

PCMs in building systems may be incorporated directly into building components such as walls that offer large areas of contact with the outer environment, and therefore assist effectively in buffering heat exchanges. One relevant way of incorporating PCM regards to rendering mortars, which are cheap and can be used in a wide variety of applications [33]. The incorporation of PCM into a mortar involves its initial encapsulation, as to avoid leakage or permeation problems of the PCM within the mortar [23]. Previous studies of the authors have shown that PCM mortars can include large quantities of PCM, reaching nearly as much as 20 wt.\% of total mass of the mortar [34].

According to literature, excepting the recent papers of the authors concentrated on material level investigation [31,32], no previous research has been found to study the feasibility of hybrid PCM (i.e. incorporating more than one types of PCM with distinct melting temperature and enthalpies in the same mortar) to enhance the efficiency of the PCM system. However, hybrid PCM may bring an extra benefit for PCM systems that aims an efficient energy saving compared to situations in which PCM is not used at all, or even situations in which only a single type of PCM is embedded into the mortar. Therefore, it is considered advisable to test the concept in a real scale application, in order to assess thermal behavior as well as energy saving potential of hybrid PCM mortar.

In order to assess the energy efficiency gains for space heating that can be obtained through the use of PCMs embedded in the mortar of internal coatings for buildings, three test cases of an hypothetical test building were considered in regard to the composition of the interior coating mortar of external walls: (i) one in which a hybrid PCM mortar is used (here termed as HPCMM); (ii) another in which a single PCM mortar is used (here termed as SPCMM); and (iii) the case in which a regular mortar is used (here termed as REFM). The three cases were subjected to simulated real temperature variation, thus allowing evaluating the differences in thermal performance induced by the three types of tested mortars which consequently allowing energy saving assessment through real scale tests.

\subsection{Materials of the wall system}

Mortars with PCM (HPCMM or SPCMM) with nearly 20\% of PCM as compared to the global mass of the mortar were considered [32]. The formulation of mortars HPCMM adopted herein contains three distinct PCMs, as opposed to previous works of this research team in which only two distinct PCMs had been used [31,32]. Moreover, the formulation of SPCMM previously used in Ref. [31] was considered.

The studied HPCMM incorporates a combination of three PCMs with melting temperatures of $5{ }^{\circ} \mathrm{C}, 21^{\circ} \mathrm{C}$ and $23^{\circ} \mathrm{C}$. These three PCMs are considered in equal mass fractions, thus globally reaching $18.34 \%$ of the weight of the mortar. The SPCMM incorporates only one type of PCM with melting temperature of $20^{\circ} \mathrm{C}$ which contains $18.34 \%$ weight percentage of PCM within the mortar.

The main thermo-physical properties of the materials used in all mortar cases, REFM, SPCMM and HPCMM, are synthesized in Table 1, obtained with basis on previous experimental works [35]. It is noted that the specific heat capacity of HPCMM was estimated with basis on the results obtained for a similar mortar which had PCM melting temperatures of $10^{\circ} \mathrm{C}, 26^{\circ} \mathrm{C}$ and $28^{\circ} \mathrm{C}$ (previously tested in [35]). Furthermore, the specific heat capacity of SPCMM was estimated with basis on the experimental results 
Table 1

Thermo-physical properties of the materials used in the numerical simulations.

\begin{tabular}{|c|c|c|c|c|c|c|c|}
\hline Thermo-physical properties & Units & Regular mortar & Single PCM mortar & Hybrid PCM mortar & XPS [36] & Brick [37] & Air [38] \\
\hline Density & $\left(\mathrm{kg} / \mathrm{m}^{3}\right)$ & 1529.5 & 1360.9 & 1309.8 & 32 & 1976 & Ideal-gas \\
\hline Thermal conductivity & $(\mathrm{W} / \mathrm{m} \mathrm{K})$ & 0.4 & 0.3 & 0.3 & 0.034 & 0.77 & 0.0242 \\
\hline Specific heat capacity & $(\mathrm{J} / \mathrm{kg} \mathrm{K})$ & 1000 & See Fig. 1a & See Fig. 1b & 1400 & 835 & 1006.43 \\
\hline
\end{tabular}

obtained for a similar mortar that incorporated with single PCM with melting temperature of $24^{\circ} \mathrm{C}$ (previously tested in [31]).

It is usually desirable that the melting temperatures of the PCMs are in the vicinity of the intended comfort temperature, as to ensure that the phase-change process happens in a frequent manner. Therefore, the experimentally obtained specific heat capacity curves for SPCMM and HPCMM were found to be inadequate for a desirable comfort temperature of $20^{\circ} \mathrm{C}$. In view of that, it was decided to shift the experimentally obtained specific heat capacity curves of SPCMM and HPCMM by $5{ }^{\circ} \mathrm{C}$ and $4{ }^{\circ} \mathrm{C}$ to the left in order to have the peaks closer to the intended temperature range respectively (e.g., $20^{\circ} \mathrm{C}$ ) as shown in Fig. 1. Table 1 also contains information about the XPS (extruded polystyrene) [36], brick [37] and air [38] that were part of the considered wall system.

\subsection{Simulation mode}

A simplified five story building located in Portugal is considered for simulation, see Fig. 2a. The entire third floor is analyzed, assuming that no thermal exchanges occur on both bottom and upper slabs (i.e. adiabatic conditions). As shown in Fig. 2b and c, the volume of study of the third floor has inner dimensions of 9.71 (length) $\times 9.71$ (width) $\times 3 \mathrm{~m}$ (height). The exterior walls, schematically represented in Fig. 2b, have a typical layout characterized by (from outside to inside): a $0.02 \mathrm{~m}$ thick of plastering mortar (REFM), $0.1 \mathrm{~m}$ of brick, a $0.03 \mathrm{~m}$ of extruded polystyrene (XPS), another $0.1 \mathrm{~m}$ thick of brick and a $0.02 \mathrm{~m}$ of plastering mortar (REFM or HPCMM) as inner lining. The simulated model equipped with a heater unit that has a heated area of $3.29 \mathrm{~m}^{2}$ with a power of $1500 \mathrm{~W}$ placed at the geometrical center of the model. The composition of the walls of the model is a typical one in Portuguese building envelopes. In fact, the target in this case was to have a real-sized dimension, which would however have a thermal transmittance $\left(U \approx 0.7 \mathrm{~W} / \mathrm{m}^{2} \mathrm{~K}\right)$ lower than the maximum limit according to Portuguese regulations for vertical elements (of $U=1.45 \mathrm{~W} / \mathrm{m}^{2} \mathrm{~K}$ ) [39]. The point labeled as monitoring point in Fig. $2 \mathrm{~b}$ and $\mathrm{c}$ was used as the reference control point for the thermostat of the heating unit and for the temperature analyses presented in this paper. The heating unit was set to maintain the internal temperature at the desirable comfort temperature of
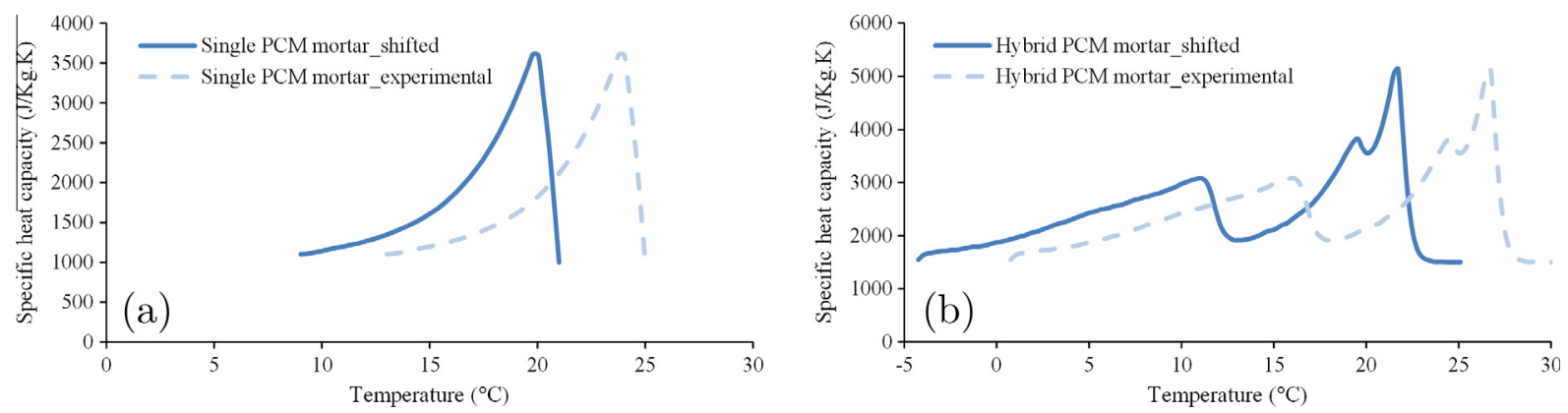

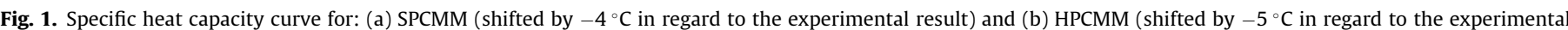
result).

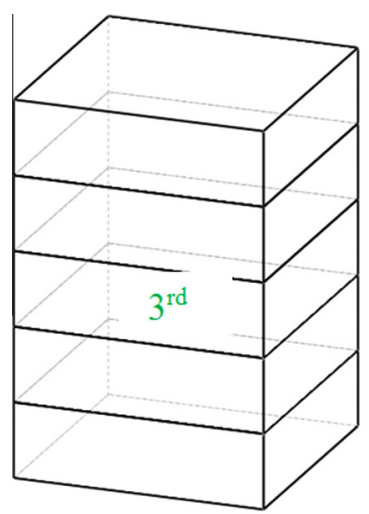

(a)

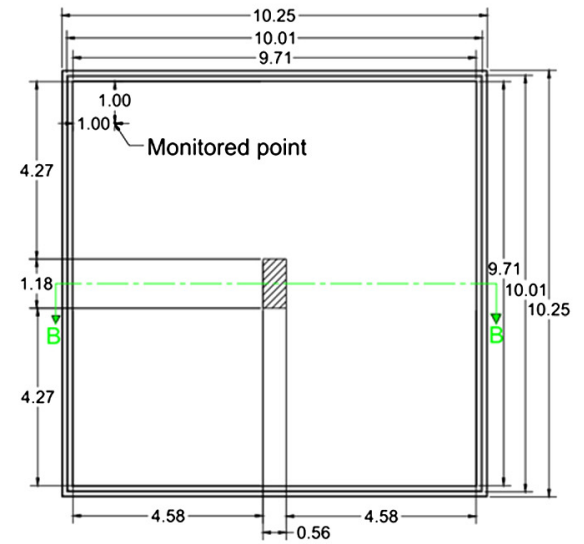

(b)
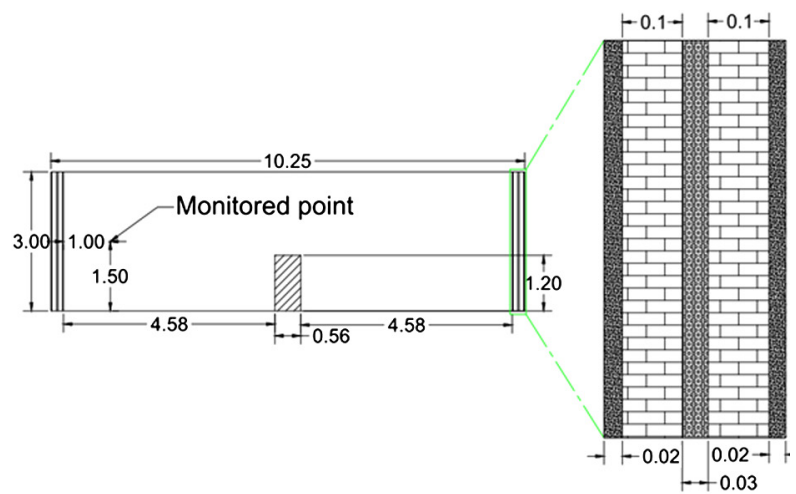

(c) (d)

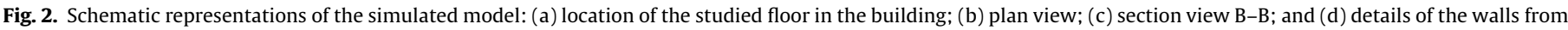
exterior to the interior (REFM; brick; extruded polystyrene (XPS); brick; REFM or HPCMM). Units: [m]. 


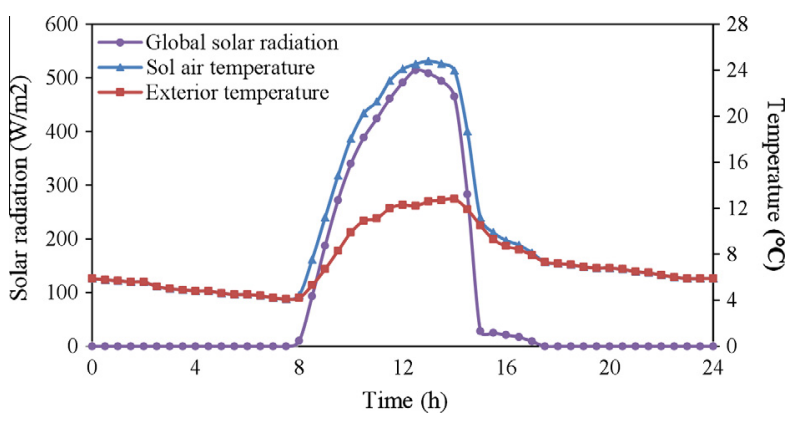

Fig. 3. Exterior temperature, solar radiation and solair temperature (south-oriented wall) for a winter day in Guimarães, Portugal.

$20^{\circ} \mathrm{C}$, according to the recommendations of ASHRAE 55 [40]. The operating principle of the heater's thermostat is a simple ON/OFF algorithm with the set-point of $20^{\circ} \mathrm{C}$ : the heater is turned $\mathrm{ON}$ when the temperature inside becomes lower than $20^{\circ} \mathrm{C}$ and it is turned OFF when the temperature reaches $20^{\circ} \mathrm{C}$ again.

A winter scenario was studied in this research, corresponding to the location of Guimarães in the North of Portugal. Solar radiation effects were considered in a simplified manner through a sol-air temperature algorithm, according to methodology detailed in [41]. As a result of the application of the solair temperature algorithm, the $24 \mathrm{~h}$ cycles shown in Fig. 3 were obtained for winter scenario.

The general transient heat balance equation [38] was applied for the numerical treatment of the heat transfer processes in the solid parts of the studied model. All involved materials are considered homogeneous and isotropic. The effect of natural convection due to potential convective flows inside the model was considered through computational fluid dynamics (Navier-Stokes equations) [42]. Phase changes were modeled through a simplified approach by which the energy release/absorption associated to the phase change process is considered through artifacts applied to the specific heat capacity term. This strategy of simulation of the enthalpy of phase change consists in increasing the heat capacity value of the mortar during such process, and is usually termed "effective heat capacity method" [43]. The Navier-Stokes equations are discretized through the Finite Volume Method (FVM) using ANSYSFLUENT software [44]. The external surfaces of the flat are bounded by convective heat transfer conditions. A value of $20 \mathrm{~W} / \mathrm{m} \mathrm{K}$ [45] was considered for the surface convection coefficient. In the top and bottom planes, adiabatic boundaries were considered. A boundary condition heat flux of $454 \mathrm{~W} / \mathrm{m}^{2}$ is applied to the model heater unit, together with the ON/OFF algorithm for its operation. The exterior lateral surfaces of the walls (except for the top and

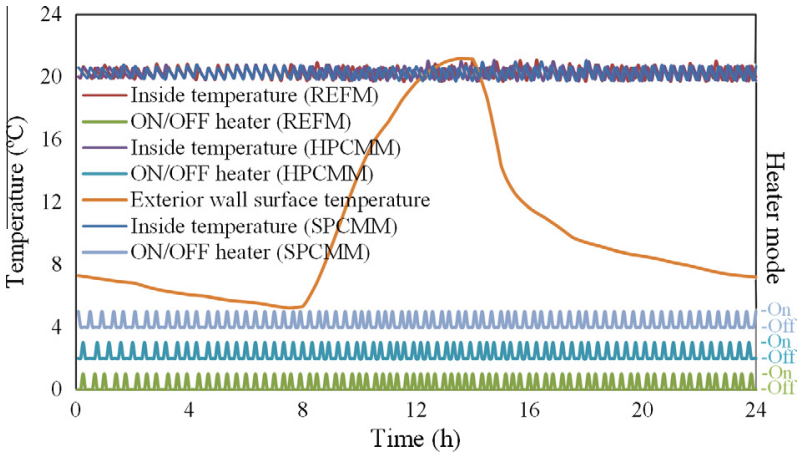

Fig. 5. Interior temperature of the flats with and without hybrid PCM controlled with heater unit system.

bottom plans), were assigned with convective thermal boundary conditions, taking into account the varying temperature imposed in the model. In all the cases, the model was initialized from $20^{\circ} \mathrm{C}$. A total of two simulations were conducted by submitting the each case to winter scenario testing, with each simulating lasting three full day cycles ( $72 \mathrm{~h}$ ), with the analysis of this paper incident on the second stabilized cycle. A constant time step size of $300 \mathrm{~s}$ was considered. The convergence criterion at each time step was checked under $10^{-3}$ for momentum equation, $10^{-2}$ continuity equation and $10^{-5}$ for and energy equations [46]. The standard $k-\epsilon$ turbulence model, were used and air was considered as an ideal gas. The mesh of the model is structured, being comprised of hexahedral cells as shown in Fig. 4.

Fig. 5 shows the temperature variation of the "monitored point for the SPCMM, HPCMM and REFM scenarios. Even though it is not directly noticeable from the figure, the heater is turned on for a total of $6.5 \mathrm{~h}$ per day for the REFM scenario, whereas the SPCMM and HPCMM scenarios allowed reductions of the heating time to $6.25 \mathrm{~h}$ and $6.08 \mathrm{~h}$, which by itself represents $4 \%$ and $7 \%$ saving alone, respectively. These results indicate that HPCMM can have better potential of energy saving when compared with single PCM type (SPCMM). Even though the potential energy saving of the SPCMM scenario was already quite satisfactory, the HPCMM has added value without predictable added cost, and therefore no further discussions will be made on the SPCMM scenario.

\section{Modeling the demand response programs}

DRPs aim to make consumers more sensitive to variations of electricity prices in different hours. DRPs encourage electricity consumers to change their electricity use in response to fluctuations of
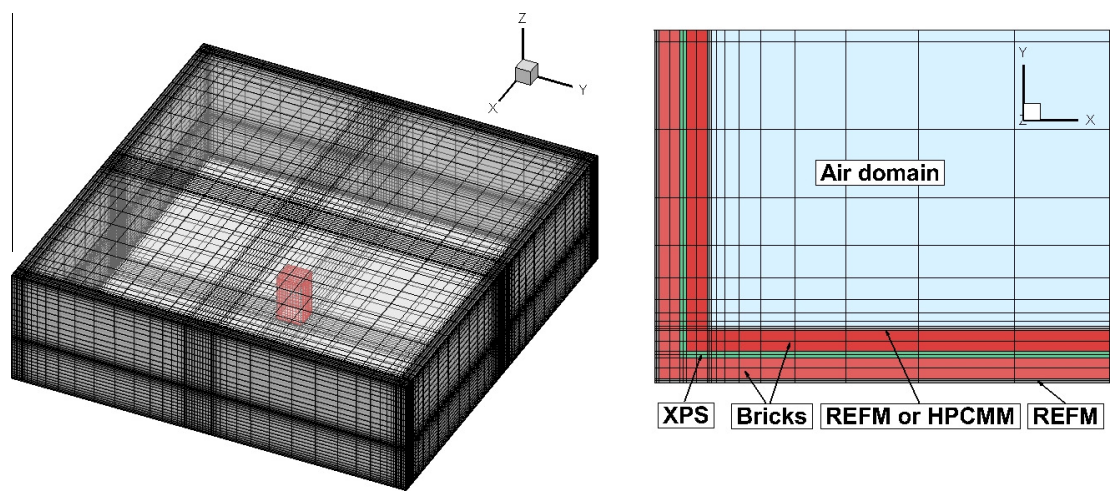

Fig. 4. 3D mesh of the simulated model and mesh distribution in walls and air boundary layer. 


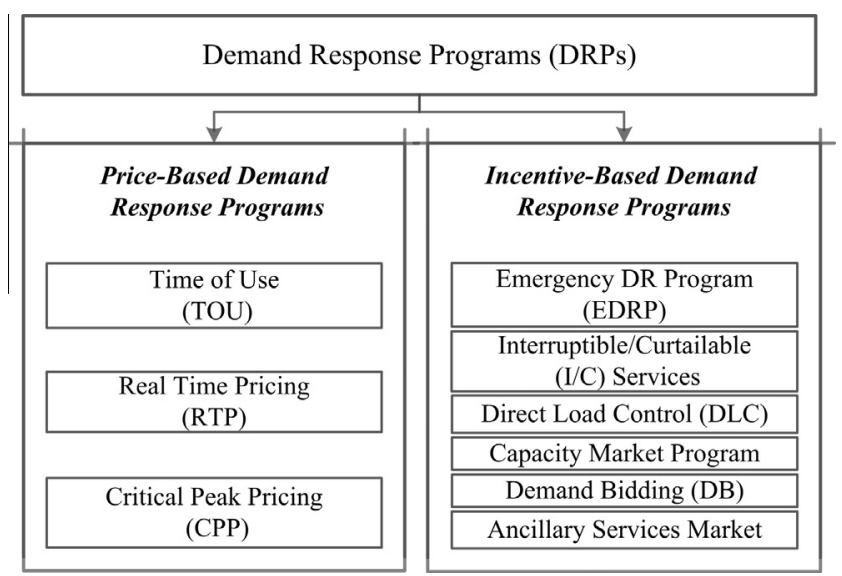

Fig. 6. Classification of demand response programs.

price over the time, or to offer incentives, or to charge penalties that are considered to provide lower use during high electricity prices or when the power system reliability is threatened. DRPs can be categorized into two major groups, namely, price-based programs, and incentive-based programs. Each mentioned group can also be categorized into some subsets as illustrated in Fig. 6 . Details of the DRPs have been discussed in [47]. In this paper, both groups of DRPs are considered from the consumers' point of view by using the mathematical formulation as described below:

Assuming that the customer's electricity demand at hour $t$ is changed from $d_{t}^{i n i}$, initial amount of demand, to $d_{t}$, due to price changes or an incentive payment or a penalty consideration, the impacts of DRPs on a customer's consumption can be formulated as below:

$\Delta d_{t}=d_{t}^{\text {ini }}-d_{t}$

The amount of incentive, $\varsigma_{t}$, is expressed as:

$\varsigma_{t}=\operatorname{Inc} c_{t} \Delta d_{t}$

Similarly, the amount of penalty, $\xi_{t}$, can be formulated as:

$\xi_{t}=\operatorname{Pen}_{t}\left(d_{t}^{\text {Cont }}-\Delta d_{t}\right)$

where $d_{t}^{\text {Cont }}$ denotes the contract level for hour $t$.

The customer's benefit, $B$, at hour $t$ can be as follows [48]:

$B_{t}=\operatorname{Re} v_{t}-d_{t} \lambda_{t}+\operatorname{Inc}_{t} \Delta d_{t}-\operatorname{Pen}_{t} \Delta d_{t}$

where $\operatorname{Re} v_{t}$ is the customer's revenue at hour $t$ that is a function of amount of demand, $d_{t}$.

The total benefit of the customer during time interval, $T$, can be formulated as bellow:

$B_{\text {tot }}=\sum_{t=1}^{T}\left(\operatorname{Rev}_{t}-d_{t} \lambda_{t}+\operatorname{Inc}_{t} \Delta d_{t}-\operatorname{Pen}_{t} \Delta d_{t}\right)$

Eq. (5) represents a general model to calculate the decision variable of the customer's benefit for both price-based and incentivebased DRPs containing both single- and multi-period responses. The total benefit, $B_{t o t}$, expresses the main variable of a responsive demand to decide how to respond to price and incentive/penalty changes. In the next section, this general model is particularly applied to a specific customer, i.e. a responsive residential demand.

\section{Modeling the responsive smart household}

The block diagram of a typical smart household is presented in Fig. 7. As it can be seen in Fig. 7, the HEM system controls the operation of the smart household regarding the signals from Load Serving Entity (LSE), DRPs, charging/discharging of batteries, consumption of critical and controllable loads.

DR providers attempt to change the load pattern of their customers. Therefore, each responsive smart household is motivated to adjust its electricity consumption profile. In a fixed rate tariff, the consumer tends to use its appliances at the most convenient time, associated with its personal preference. For instance, a majority of customers use the air conditioning systems during the warmest hours of a day, hence causing the demand peak. In the proposed model, monetary incentive/penalty offered by the DR provider encourages the habitants to change their consumption profile. The objective of customers maximizes the net payoff [16]. On this basis, in the proposed model, the objective is to maximize the incomes of selling energy to the grid (if it is possible) and incentives of DRPs, minus the costs of buying energy from the grid, penalties of DRPs, degradation of battery and dissatisfaction of getting distance from the reference consumption, as presented in (6):

$$
\begin{aligned}
\underset{P_{t}^{\mathrm{G} H}, P_{t}^{H 2 G}, \operatorname{Cos}_{t}^{\text {Degr }}, V_{t}}{\operatorname{Maximize}}\left\{\text { profit }^{\text {Household }}\right\}= & \sum_{t}\left\{P_{t}^{G 2 H}\left(\lambda_{t}^{i n i}-\lambda_{t}\right)\right. \\
& -P_{t}^{H 2 G}\left(\lambda_{t}^{i n i}-\lambda_{t}\right)-\operatorname{Cost}_{t}^{\text {Degr }} \\
& \left.+\operatorname{Inc}_{t} \Delta P_{t}^{G 2 H}-\operatorname{Pen}_{t} \Delta P_{t}^{G 2 H}-V_{t}\right\}
\end{aligned}
$$

The first two terms of (6) represent the buying cost and selling income obtained from trading the energy with the grid, respectively. The third term denotes the owner's cost associated with degradation of its batteries resulted from operation in $B 2 G$ or $\mathrm{B} 2 \mathrm{H}$ modes. The battery degradation cost can be given by (7).

$\operatorname{Cost}_{t}^{\text {Degr }}=\left(P_{t}^{B 2 H}+P_{t}^{B 2 G}\right) C_{d}$

where $\operatorname{Cost}_{t}^{\text {Degr }}$ is the household's daily equipment degradation cost arisen from operating in $B 2 G$ or $B 2 H$ modes and $C_{d}$ is the battery cost that is considered as the depreciation because of extra cycling of the battery in $B 2 G$ or $B 2 H$ modes and can be calculated by (8).

$C_{d}=\frac{\operatorname{Cost}_{B}}{L_{E T}}$

It should be noted that considering the degradation cost of batteries not only maintain the life time of batteries but also causes that the proposed HEM system serves the requirement of a priority in discharging the batteries. In other words, HEM system changes the controllable loads before discharging the batteries, if the appropriate level of habitants' satisfaction is met.

The fourth and fifth terms of (6) are respectively related to the incentive income and penalty cost due to participate in the incentive-based DRPs. $\Delta P_{t}^{G 2 H}$ is defined as the initial energy that the household receives from the grid (i.e. in a fixed rate tariff) minus the received energy in an incentive-based DRP. Finally, the last term, $V_{t}$, denotes a function that obtains the dissatisfaction caused by the deviation from the reference consumption and can be formulated by (9).

$V_{t}=v^{A p p}\left(P_{t}^{C n t r l}-P_{t}^{i n i, C n t r l}\right)+v^{B}\left[\left(P_{t}^{G 2 B}-P_{t}^{i n i, G 2 B}\right)+\left(P_{t}^{i n i, B 2 G}-P_{t}^{B 2 G}\right)\right]$

where $P_{t}^{\text {Cntrl }}$ denotes the controllable load and $v \geqslant 0$ represents an inelasticity parameter of demand [16]. Since the differential dissatisfaction of a household is increased by getting distance from the reference controllable load, $V_{t}$ is considered a convex function [16].

$P_{t}^{\text {ini,Cntrl }}$ is defined as the reference consumption pattern of controllable part of demand that can indicate the preferred consumption pattern without DRPs. Both types of price-based and 


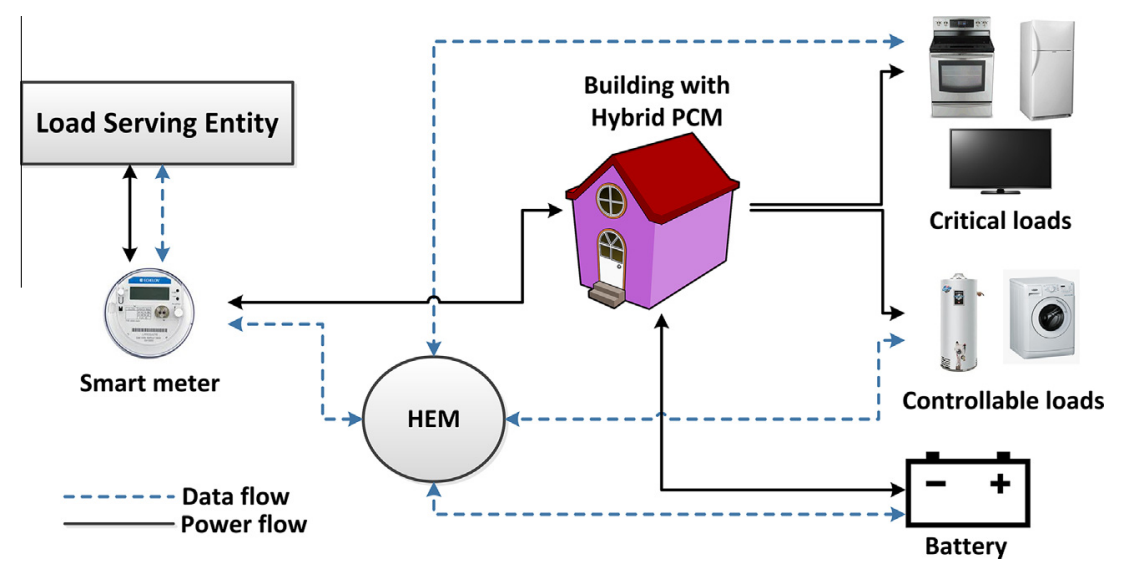

Fig. 7. Block diagram of a typical smart household.

incentive-based DRPs can motivate the customer to change the demand due to monetary reasons.

The objective function is minimized by considering the constraints as expressed below:

$P_{t}^{G 2 H}+\chi_{t}^{B}\left(P_{t}^{B 2 H}+P_{t}^{B 2 G}\right)=P_{t}^{C n t r l}+P_{t}^{C r i t}+\gamma_{t}^{B} P_{t}^{G 2 B}$

where $P_{t}^{\text {Crit }}$ is defined as the critical part of the household demand and it is assumed to be unchangeable and consequently independent of the DRPs.

Eq. (10) denotes that the demand consisting of the residential load $\left(P_{t}^{C n t r l}\right.$ and $\left.P_{t}^{\text {Crit }}\right)$ and the charging requirements of the batteries $\left(P_{t}^{G 2 B}\right)$, is either satisfied by the purchased energy from the grid $\left(P_{t}^{G 2 H}\right)$ or by the internal generation of batteries. $\chi_{t}^{B}$ and $\gamma_{t}^{B}$ are binary variables and ensure that the batteries cannot be charged and discharged at the same time as (11).

$\chi_{t}^{B}+\gamma_{t}^{B}=1$

The hourly amount of controllable loads equals to the sum of consumption of each controllable appliance as formulated in (12). It is assumed that the consumption power of each controllable appliance equals to its nominated amount and HEM manages the controllable loads by arranging the ON/OFF state of the appliances, $s_{i, t}^{A p p}$, as presented in (13).

$P_{t}^{C n t r l}=\sum_{i}\left\{P_{i, t}^{A p p}\right\}$

$P_{i, t}^{A p p}=s_{i, t}^{A p p} P_{i}^{N o m}$

Eq. (14) ensures the daily consumption of each controllable appliance not to be more than the required consumption of that appliance.Although the dissatisfaction function, $V_{t}$, models the tendency of consumers not to change their usage pattern, an operation time is also defined for each controllable appliance that guarantees the appliance to be operated during an acceptable period by the consumer.

$P_{i}^{R e q} l e \sum_{t}\left\{P_{i, t}^{A p p}\right\} \quad t \in T_{i}^{A c c}$

Most of appliances, such as washing machine, should not be switched off during the operation. In other words, the HEM system should respect that working period of appliances. To this end, Eqs. (15)-(17) ensure that each controllable appliance is continuously operated in its working period.

$$
\begin{aligned}
& \alpha_{i, t}+\sum_{j=1}^{W P_{i}-1}\left\{\beta_{i, t+j}\right\} \leqslant 1 \\
& \alpha_{i, t}-\beta_{i, t}=s_{i, t}^{A p p}-s_{i, t-1}^{A p p} \\
& \alpha_{i, t}+\beta_{i, t} \leqslant 1
\end{aligned}
$$

where $\alpha_{i, t}$ and $\beta_{i, t}$ are auxiliary binary variables.

$$
\begin{aligned}
& S O C_{t}=S O C_{t-1} \gamma_{t}^{B} \eta^{c h}\left(\frac{P_{t}^{B, c h}}{C_{a p^{B}}}\right)-\chi_{t}^{B}\left(\frac{P_{t}^{B 2 H}+P_{t}^{B 2 G}}{\eta^{\text {dis }} C a p^{B}}\right) \\
& 0<S O C^{\min } \leqslant S O C_{t} \leqslant S O C^{\max }<1 \\
& r_{t}^{c h}=\frac{S O C_{t}-S O C_{t-1}}{\eta^{c h}} \\
& r_{t}^{d i s}=\left(S O C_{t-1}-S O C_{t}\right) \eta^{\text {dis }} \\
& 0 \leqslant r_{t}^{c h} \leqslant r^{c h, \text { max }} \\
& 0 \leqslant r_{t}^{d i s} \leqslant r^{d i s, \text { max }}
\end{aligned}
$$

Eq. (18) introduces changes in State Of Charge (SOC) of batteries. Eq. (19) is employed to avoid being overcharged and to consider the depth of discharge of batteries. The constraints of maximum charging/discharging rates are presented in Eqs. (20)(23).

The total sold power equals to the surplus of the injection of batteries in $B 2 G$ mode, as presented in (24).

$P_{t}^{H 2 G}=P_{t}^{B 2 G}$

The received consumption/generation limit signals from the distribution transformer are compared with the traded power of the household by the HEM control center [3]. Eqs. (25) and (26) ensure that the traded power between the house and grid not to exceed the line or grid limits. $P_{t}^{G, \max }$ enforces a limit on the drawn power from the grid and the injected power to the grid.

$\chi_{t}^{H} P_{t}^{G 2 H}+\gamma_{t}^{H} P_{t}^{H 2 G} \leqslant P_{t}^{G, \max }$

$\chi_{t}^{H}+\gamma_{t}^{H}=1$

where $\chi_{t}^{H}$ and $\gamma_{t}^{H}$ are binary variables and guarantee that the household cannot be fed while injecting the energy back to the grid.

\section{Numerical results}

The proposed model is tested on a household that participates in the Iberian electricity market [49]. According to [49], the hourly prices of energy market in January 2014 are illustrated in Fig. 8. The hours between 1 and 8 are considered as valley period. The 


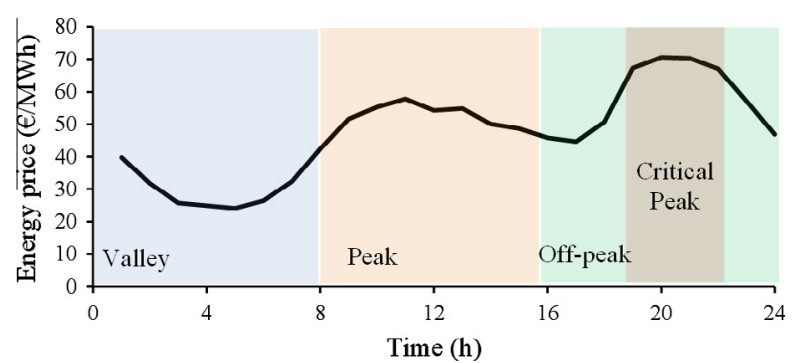

Fig. 8. Hourly prices of the energy market.

Table 2

Electricity tariffs for the price-based demand response programs ( $€ / \mathrm{kWh}$ ).

\begin{tabular}{lllll}
\hline Case & Valley & Off-peak & Peak & Critical peak \\
\hline Base case (fixed rate tariff) & 0.047 & 0.047 & 0.047 & 0.047 \\
TOU & 0.024 & 0.047 & 0.063 & 0.071 \\
CPP & 0.047 & 0.047 & 0.047 & 0.150 \\
RTP & As indicated in Fig. 8 & & \\
\hline
\end{tabular}

hours 9-16 are peak period. The hours between 19 and 22 form critical peak period, while the remainder hours denote off-peak period.

In order to study the operational behavior of the household, various price-based and incentive-based DRPs are considered, as respectively presented in Tables 2 and 3.

As it can be seen in Table 2, in the base case a fixed rate tariff is considered equal to the average of hourly prices that presents the behavior of the household energy management system without participation in any DRPs. A type of TOU is taken into account in which the considered tariff in valley period is half the off-peak tariff, and the peak and critical peak tariffs is 30\% and 50\% higher than off-peak tariff, respectively. The off-peak tariff is considered equal to the average of hourly prices (i.e. equal to the fixed rate tariff). In CPP program, a large amount of price, $150 € / \mathrm{MW} \mathrm{h}$, is set for the critical peak period. In Table 3, two incentive-based DRPs are presented. In EDRP case, an incentive equal to $25 \%$ of average price, i.e $0.012 € / \mathrm{kW} \mathrm{h}$, is considered for the load reduction. On this basis, if the responsive customer decreases its demand during the critical peak period, it receives the mentioned amount of incentive. In the $\mathrm{I} / \mathrm{C}$ services, it is assumed that a signal sends to the HEM to reduce the household demand for one hour. It is assumed that the amount of the load curtailment in the critical peak hours is twice of the one in the peak hours.

The household batteries are assumed to have $3 \mathrm{~kW}$ h capacity. The details of the batteries are presented in Table 4. It is assumed that the consumer tends to operate the water heating twice a day at hours 7:00 and 22:00, while these times can be changed based on the acceptable times by the consumer, i.e. 5:00-7:00 and 19:00-22:00, considering the dissatisfaction factor equals to 5 cent $/ \mathrm{kW}$ h. It should be noted that, the dissatisfaction function is not applied on the space heating, because, the space heating set point is considered $20^{\circ} \mathrm{C}$ that ensures the satisfaction of the consumers in winter. In addition to the lighting load dedicated in the critical part of load, five extra lamps are assumed to be used by the habitants in their highest satisfaction level that can be con-
Table 4

Details of household batteries.

\begin{tabular}{lll}
\hline$r^{\text {ch,max }}(\mathrm{pu} / \mathrm{h})$ & $r^{\text {dis,max }}(\mathrm{pu} / \mathrm{h})$ & $\eta^{\text {ch }}$ \\
0.2 & 0.2 & 0.9 \\
$\eta^{\text {dis }}$ & $\operatorname{SOC}^{\min }$ & $\operatorname{SOC}^{\max }$ \\
0.82 & 0.3 & 0.9 \\
SOC $^{\text {ini }}$ & $\operatorname{Cost}_{B}(€)$ & $L_{E T}(\mathrm{MW} \mathrm{h})$ \\
0.5 & $900^{*}$ & $43840^{* *}$ \\
\hline
\end{tabular}

$300(€ / \mathrm{kW} \mathrm{h}) \times 3(\mathrm{~kW} \mathrm{~h})$.

** A deep depth of discharge is assumed [50].

sidered as controllable loads. The characterization of other household appliances is presented in Table 5. The critical load data are extracted from the consumption of a typical $100 \mathrm{~m}$-square house in Portugal in January as illustrated in Fig. 9. The optimization problem is modeled as a Mixed Integer Linear Programming (MILP) and is solved by CPLEX12.

The consumption of the space heating with and without implementation of hybrid PCM is indicated in Fig. 10. As it can be seen, the proposed hybrid PCM causes that the daily space heating consumption to be reduced. In addition, this thermal storage system shifts the electricity consumption in some hours. For example, the hybrid PCM can maintain the temperature by consuming $0.375 \mathrm{~kW} / \mathrm{h}$ between hours 18 and 24, while the regular system requires to increase the consumption up to $0.5 \mathrm{~kW} / \mathrm{h}$ in hours 20 and 23 in order to keep the inside temperature comfortable. In addition, between hours 11 and 17 , the regular system requires to increase the heating from $0.375 \mathrm{~kW} / \mathrm{h}$ to $0.5 \mathrm{~kW} / \mathrm{h}$ for five hours, whereas the hybrid PCM enables the space heating to provide the same comfort level by three hours increase of the heating consumption.

The household demand in different DRPs is illustrated in Fig. 11. This figure indicates the hourly consumption of the electrical appliance by considering the proposed HEM system and hybrid PCM mortar. According to Fig. 11a, implementation of TOU program reduces the peak-to-valley distance and causes the demand curve to become flatter. On this basis, the HEM system shifts the dishwasher operation from the critical peak period to hour 8 in the valley period. In addition, the non-critical lamps during critical peak are decided to become off. However, operation time of washing machine is not changed. Based on the limits on the operation times, washing machine can only be operated between hours 18 and 23. Since the working period of the washing machine is $120 \mathrm{~min}$, if the HEM system shifts it out of the critical peak period, only one hour of its operation is placed on the off-peak period and another hour of its working still stands on the critical peak. This causes that this shifting option is not selected due to its dissatisfaction cost. Dissatisfaction cost of water heating is also too high to permit the HEM system to shift it from hour 22 to hour 18. In addition, the battery is charged twice, once during the valley and then during the off-peak period.

According to Fig. 11b, the CPP program can also decrease the peak-to-valley distance. Because of the high tariff, the HEM system prefers to shift all loads out of the critical peak period, even though the dissatisfaction cost of changing the operation time of water heating is high. On contrary to TOU program, CPP causes that the

Table 3

Considered cases for the incentive-based demand response programs.

\begin{tabular}{|c|c|c|c|c|}
\hline Case & Valley & Off-peak & Peak & Critical peak \\
\hline EDRP & - & - & - & $0.012 € / \mathrm{kW} h$ incentive for demand reduction \\
\hline $\mathrm{I} / \mathrm{C}$ services & - & - & $5 \%$ load curtailment for one hour & $10 \%$ load curtailment for one hour \\
\hline
\end{tabular}


Table 5

Details of household controllable appliances.

\begin{tabular}{|c|c|c|c|c|c|c|}
\hline Appliance & No. & $W P(\mathrm{~m})$ & $P_{i}^{\text {Nom }}(\mathrm{kW})$ & $T_{i}^{i n i}(\mathrm{~h})$ & $T_{i}^{A c c}(\mathrm{~h})$ & $v^{A p p}($ cent $/ \mathrm{kW} \mathrm{h})$ \\
\hline Washing machine & 1 & 120 & 0.5 & 20 & $18-23$ & 1 \\
\hline Dishwasher & 1 & 60 & 1.5 & 22 & $8-23$ & 1 \\
\hline Water heating & 1 & 60 & 4.5 & 7,22 & $5-7,18-22$ & 5 \\
\hline Space heating & 1 & 5 & 1.5 & - & - & - \\
\hline Lamp & 5 & 60 & 0.08 & $18-23$ & $18-23$ & 1 \\
\hline
\end{tabular}

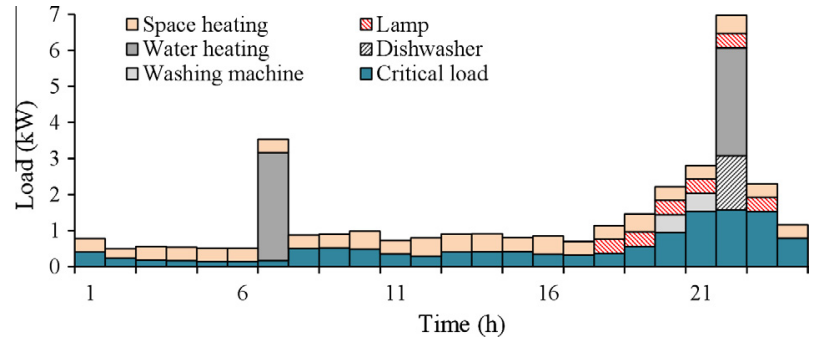

Fig. 9. Initial household demand.

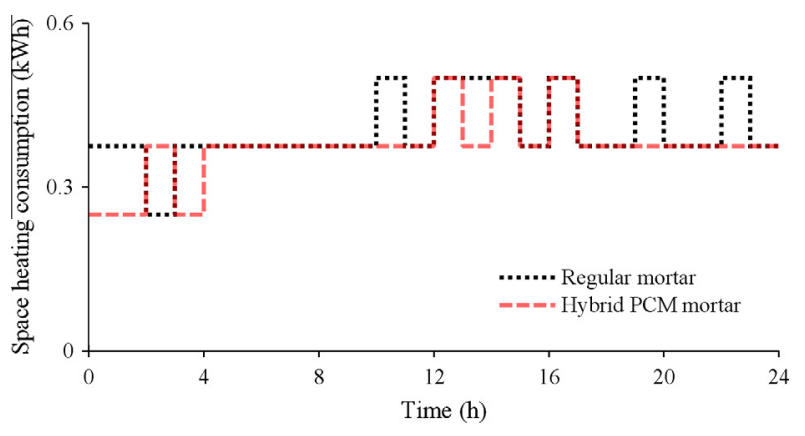

Fig. 10. Space heating consumption with and without PCM.

washing machine to be also shifted to hours 18 and 19 , because the CPP tariff is twice of the TOU one during critical peak period. Moreover, the battery is only charge once.

As it can be seen in Fig. 11c, the impact of RTP on demand curve is similar to TOU and there are only some small differences. Since the real-time price in hour 23 is $20 \%$ higher than TOU tariff, the HEM system decides to turn the non-critical lamp off in this hour. Furthermore, the hours that the battery is charged are slightly different, because the HEM selects the time with the lowest price, while in TOU program the tariff in each period is the same.

Among incentive-based DRPs, EDRP can also shift the consumption out of the critical peak period, however the peak-to-valley distance is not changed. As it can be observed in Fig. 11d, due to the incentive that is paid to the customer, the HEM system moves the water heating and dishwasher out of critical peak period. Nevertheless, this makes a new load peak at hour 23 as high as the initial load. It should be noted that, the amount of incentive is not enough to convince the HEM system to shift the operation time of washing machine. In I/C services, the shifting of dishwasher from critical peak to off-peak is significant that can show the HEM system aims to avoid the dishwasher being curtailed. It should be noted that, the battery is charged only once in both EDRP and I/C services.

According to Fig. 12, implementation of PCM causes that the HEM system's behavior in operating the battery to be changed. PCM causes the stored energy in the battery to be maintained up to hour 14, while in the case without PCM, the battery discharged at 10 and 12 in order to supply a part of household demand. In other words, the battery is operated more during the peak hours without PCM. It should be noted that, with PCM, the battery injects to home at $15,20-22$, while without PCM, the battery does not enough stored energy to inject at hour 20 . These battery injections in peak and critical peak periods can significantly mitigate the electricity cost. Moreover, it can be observed that in the case without PCM the amount of purchased energy from the gird at hour 10 is lower than the household demand. This amount of energy is supplied by the battery, as $27 \%$ reduction of battery SOC from the maximum amount can show it. In addition, $11 \%$ reduction of battery SOC is observed at hour 12 to provide some part of household demand. These amounts of battery discharge can help the HEM system to decrease the customer's cost, since hours 10 and 12 are in peak period and the high tariff is considered in TOU program. Lower consumption of space heating system with hybrid PCM in the peak period (i.e., hours 11 and 14 as illustrated in Fig. 10) enables HEM system to maintain more $38 \%(=11+27 \%)$ the stored energy in the peak period compared to the case without hybrid PCM. Then, the HEM system injects this $38 \%$ of energy saving to the household at hours 20 and 21, when the higher electricity tariff of critical peak is considered.

Tables 6 and 7 indicate the customer's cost in different cases for TOU and CPP programs, respectively. In order to show the impact of PCM and the proposed HEM model, four cases are considered. As it can be seen, using the proposed hybrid PCM mortar decreases the electricity consumption during a day. In addition, the proposed HEM system decreases the consumption because of turning off some extra lamps, while charging the battery. Incorporation of these two reduces the household consumption about $8 \%$. According to Tables 6 and 7, hybrid PCM reduces the electricity cost in most of periods, while the proposed HEM system concentrates on the peak and critical peak periods. It should be mentioned that the hybrid PCM and the proposed HEM model can respectively reduce the customer's cost $2.04 \%$ and $16.62 \%$, while incorporation of these two systems decreases the mentioned cost $20.84 \%$ that is a significant amount and $2.17 \%$ higher than impact of the two systems individually $(18.67=2.04+16.62 \%)$. Similarly, incorporation of hybrid PCM and the proposed HEM model decreases the customer's cost $48.41 \%$ that is $2.1 \%$ higher than sum of reduction of each system $(46.31=1.90+44.4 \%)$. These can show the hybrid PCM mortar and the proposed HEM model are two complementary systems, hence the hybrid PCM mortar can improve the performance of the HEM system.

According to Table 6, utilization of hybrid PCM can mitigate the household consumption from 33.36 to $32.74 \mathrm{~kW} \mathrm{~h}$ (i.e., $1.9 \%$ reduction). The proposed HEM system can reduce the consumption up to $31.82 \mathrm{~kW}$ h that is equal to $4.6 \%$ reduction. However, considering both HEM system and the hybrid PCM can have more impact and decrease the consumption to 30.82 that is equivalent to $7.6 \%$ reduction. As it can be observed, this reduction is more than the sum of hybrid PCM and HEM system individually (1.9 $+4.6=6.5 \%$ ), that can indicate the positive impact of hybrid PCM on the proposed HEM system.

The customer's cost in $24 \mathrm{~h}$ considering different DRPs is compared in Fig. 13. As it can be seen, the CPP forces the highest cost 


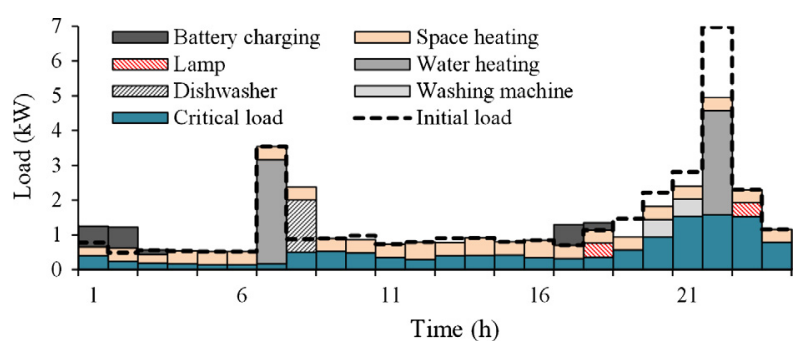

(a) TOU

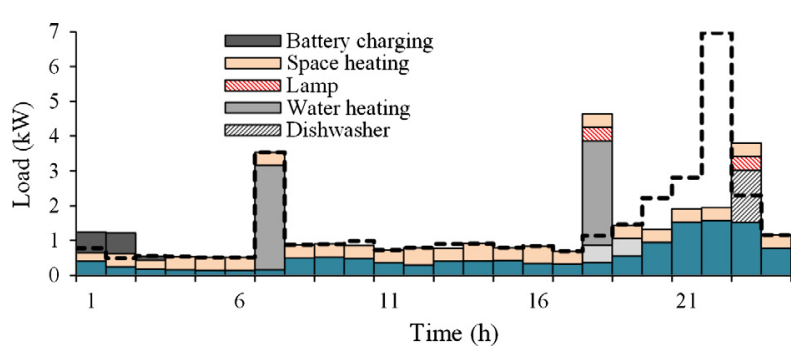

(b) CPP

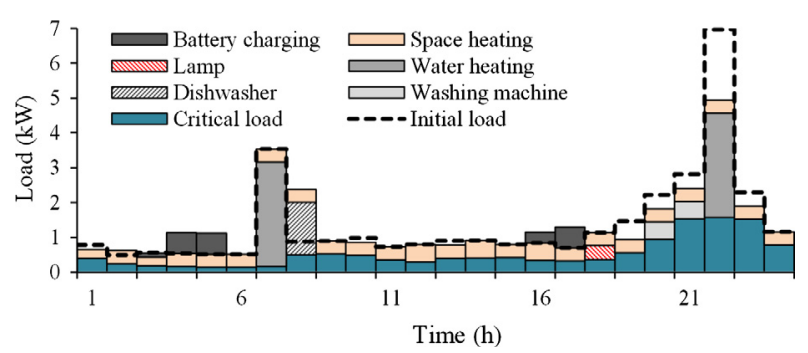

(c) RTP

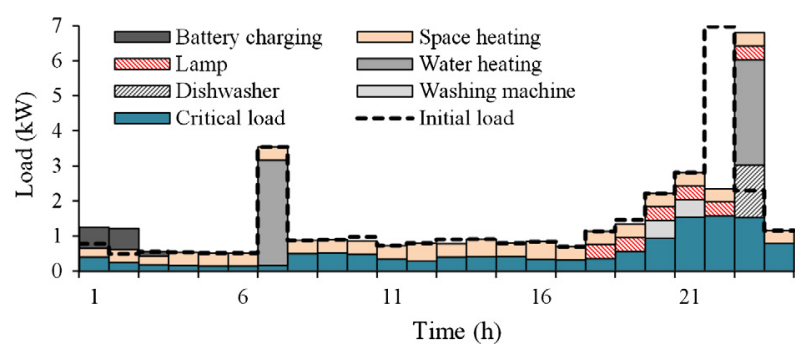

(d) EDRP

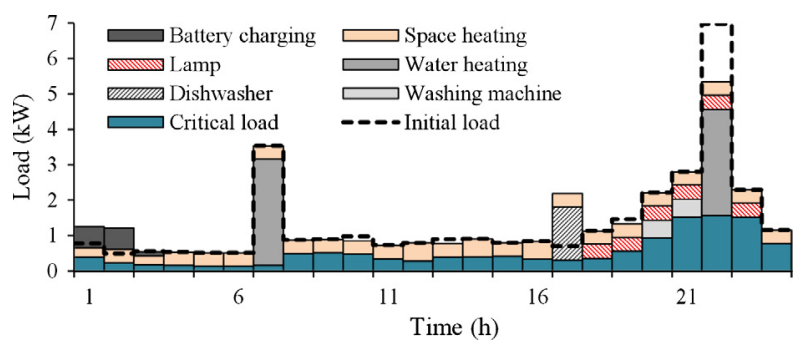

(e) I/C services

Fig. 11. Household demand considering hybrid PCM mortar and different DRPs.

to the customers, but the proposed HEM model with hybrid PCM can reduce it about $48 \%$. TOU and RTP are also two DRPs that cause high costs for the customers that can be moderated by using the proposed model.

In order to compare the obtained results with the previously reported models, the results of these models are presented in

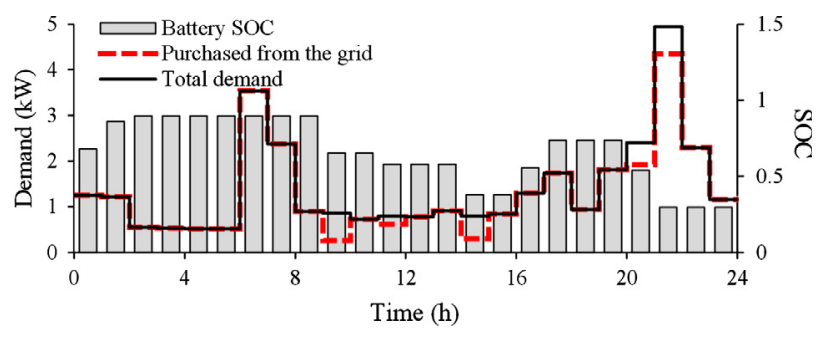

(a) Without PCM

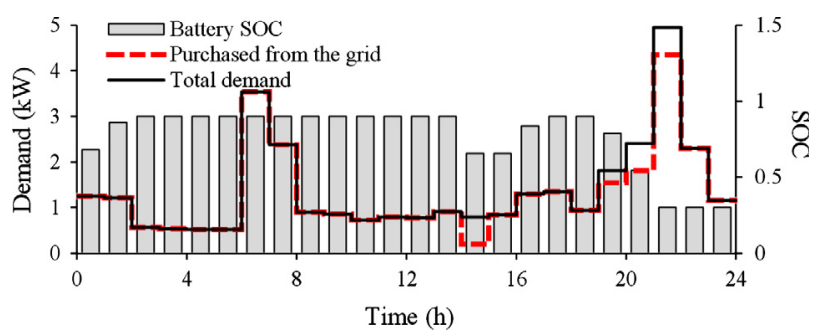

(b) With PCM

Fig. 12. The battery performance in TOU program with/without PCM.

Table 6

Customer's cost in TOU program.

\begin{tabular}{llrll}
\hline & $\begin{array}{l}\text { Base } \\
\text { case }\end{array}$ & PCM & $\begin{array}{l}\text { Proposed } \\
\text { household }\end{array}$ & $\begin{array}{l}\text { Proposed } \\
\text { household + PCM }\end{array}$ \\
\hline Consumption $(\mathrm{kW} \mathrm{h})$ & 33.36 & 32.74 & 31.82 & 30.82 \\
Cost in valley $(€)$ & 0.19 & 0.18 & 0.25 & 0.25 \\
Cost in off-peak $(€)$ & 0.25 & 0.25 & 0.31 & 0.29 \\
Cost in peak $(€)$ & 0.43 & 0.42 & 0.34 & 0.32 \\
Cost in critical peak $(€)$ & 0.96 & 0.94 & 0.67 & 0.65 \\
Total cost $(€)$ & 1.83 & 1.79 & 1.57 & 1.51 \\
Total cost reduction $(\%)$ & - & 2.04 & 16.62 & 20.84 \\
\hline
\end{tabular}

Table 7

Customer's cost in CPP program.

\begin{tabular}{lllll}
\hline & $\begin{array}{l}\text { Base } \\
\text { case }\end{array}$ & PCM & $\begin{array}{l}\text { Proposed } \\
\text { household }\end{array}$ & $\begin{array}{l}\text { Proposed } \\
\text { household + PCM }\end{array}$ \\
\hline Cost in valley $(€)$ & 0.37 & 0.36 & 0.43 & 0.43 \\
Cost in off-peak $(€)$ & 0.25 & 0.25 & 0.49 & 0.49 \\
Cost in peak $(€)$ & 0.32 & 0.31 & 0.32 & 0.31 \\
Cost in critical peak $(€)$ & 2.02 & 1.98 & 0.81 & 0.77 \\
Total cost $(€)$ & 2.96 & 2.91 & 2.05 & 2.00 \\
Total cost reduction $(\%)$ & - & 1.90 & 44.40 & 48.41 \\
\hline
\end{tabular}

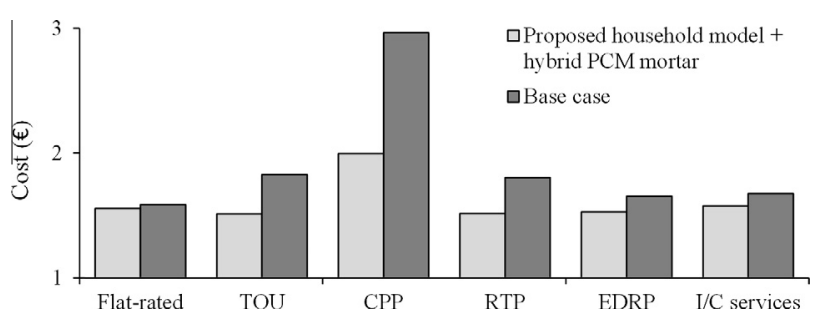

Fig. 13. Customer's cost in different DRPs.

Table 8. It should be noted that, since the studied cases of these reports (e.g., studied city/country, the month/season of study, standards of buildings, the implemented tariffs, type and size of appliances, etc.) are different, directly comparing their results is not 
Table 8

Comparison of cost reduction between different HEM models.

\begin{tabular}{|c|c|c|c|c|c|c|}
\hline \multirow[t]{2}{*}{ References } & \multirow[t]{2}{*}{ Distributed energy resources } & \multirow[t]{2}{*}{ Plug-in electric vehicles } & \multirow[t]{2}{*}{ PCM } & \multicolumn{3}{|c|}{ Cost reduction $(\%)$} \\
\hline & & & & RTP & TOU & CPP \\
\hline [16] & - & PHEV & - & $18-22$ & & \\
\hline [20] & - & PEV & - & $24-27$ & & \\
\hline [18] & - & - & - & 13.2 & & \\
\hline [19] & - & PHEV & - & $12-50$ & & \\
\hline [13] & DERs & PEV & - & 22 & & \\
\hline [51] & - & - & PCM wallboards & 11 & & \\
\hline [52] & - & - & PCM energy storage + Night ventilation & 67 & & \\
\hline [53] & - & - & PCM underfloor heating + PCM wallboards & 28.7 & & \\
\hline [54] & - & - & PCM energy storage & 58.7 & & \\
\hline [15] & - & PHEV & - & & 7 & \\
\hline [17] & - & - & - & & 18 & \\
\hline$[14]$ & Solar power & PEV & - & & 12 & \\
\hline [12] & Solar power & PEV & - & & 12.5 & \\
\hline [12] & DERs & PHEV & - & & & 22.3 \\
\hline Average & & & & 30.8 & 12.4 & 22.3 \\
\hline
\end{tabular}

appropriate, but presenting these collected results can reflect a sense of approximate impact of each reported model. Among these reports, Zhu et al. [51] studied the impacts of shape-stabilized phase change material (SSPCM) and different control strategies on the energy consumption and peak load demand as well as electricity cost of building air-conditioning systems at typical summer conditions in two climates (subtropical and dry continental climates). They concluded that, the use of SSPCM in the building could reduce the building electricity cost significantly in which, about $11 \%$ in electricity cost reduction and about $20 \%$ in peak load reduction, under two pricing policies by using load shifting control and demand limiting control respectively.

According to the literature, an HEM system could reduce operational cost of electricity by $20.4 \%, 12.4 \%$ and $22.3 \%$ (average of the reported cost reduction in the references presented in Table 8) in RTP, TOU and CPP programs, respectively. It should be noted that DERs and PEVs are both effective options to manage the customer's cost. The effective options bring some flexibility that enables HEM system to arrange the consumption optimally and even sell the surplus of these resources back to the grid. Although the capability of these resources is not considered in this paper, the proposed model can reduce the customer's cost better than the reported models.

\section{Conclusion}

This paper proposed an operational model of HEM system incorporating with a hybrid PCM to minimize the customer's cost and to ensure the habitants' satisfaction. Different case studies indicated that implementation of hybrid PCM in the buildings could affect the operational pattern of HEM systems in different DRPs. The results showed that implementation of hybrid PCM mortar could affect the electricity cost in most of hours, meanwhile the proposed HEM model had more impacts on the peak and critical peak periods. In addition, incorporation of hybrid PCM mortar had a complementary effect on the proposed HEM system. The results revealed that by utilizing the proposed model, the customer's cost could be reduced up to $48 \%$, that is significant.

\section{Acknowledgment}

The work of M. Shafie-khah and J.P.S. Catalão was supported by FEDER funds through COMPETE and by Portuguese funds through FCT, under FCOMP-01-0124-FEDER-020282 (Ref. PTDC/
EEA-EEL/118519/2010) and UID/CEC/50021/2013, and also by the EU 7th Framework Programme FP7/2007-2013 under Grant agreement No. 309048 (project SiNGULAR).

\section{References}

[1] Gellings CW. The smart grid: enabling energy efficiency and demand response. Boca Raton: CRC Press; 2009.

[2] Chen Z, Wu L, Fu Y. Real-time price-based demand response management for residential appliances via stochastic optimization and robust optimization. IEEE Trans Smart Grid 2012;3:1822-31.

[3] Shao S, Pipattanasomporn M, Rahman S. Demand response as a load shaping tool in an intelligent grid with electric vehicles. IEEE Trans Smart Grid 2011;2:624-31.

[4] Khodaei A, Shahidehpour M, Bahramirad S. SCUC with hourly demand response considering intertemporal load characteristics. IEEE Trans Smart Grid 2011;2:564-71.

[5] Tyagi V, Kaushik S, Tyagi S, Akiyama T. Development of phase change materials based microencapsulated technology for buildings: a review. Renew Sustain Energy Rev 2011;15:1373-91.

[6] Xu B, Li Z. Paraffin/diatomite composite phase change material incorporated cement-based composite for thermal energy storage. Appl Energy 2013;105:229-37.

[7] Halford C, Boehm R. Modeling of phase change material peak load shifting. Energy Build 2007;39:298-305.

[8] Su C-L, Kirschen D. Quantifying the effect of demand response on electricity markets. IEEE Trans Pow Syst 2009;24:1199-207.

[9] Tsui K. Chan S. Demand response optimization for smart home scheduling under real-time pricing. IEEE Trans Smart Grid 2012;3:1812-21.

[10] Pipattanasomporn M, Kuzlu M, Rahman S. An algorithm for intelligent home energy management and demand response analysis. IEEE Trans Smart Grid 2012;3:2166-73.

[11] Kuzlu M, Pipattanasomporn M, Rahman S. Hardware demonstration of a home energy management system for demand response applications. IEEE Trans Smart Grid 2012:3:1704-11.

[12] Pedrasa M, Spooner T, MacGill I. Coordinated scheduling of residential distributed energy resources to optimize smart home energy services. IEEE Trans Smart Grid 2010;1:134-43.

[13] Lujano-Rojas JM, Monteiro C, Dufo-Lopez R, Bernal-Agustin JL. Optimum residential load management strategy for real time pricing (RTP) demand response programs. Energy Policy 2012;45:671-9.

[14] Yu T, Kim DS, Son S-Y. Optimization of scheduling for home appliances in conjunction with renewable and energy storage resources. Int J Smart Home $2013 ; 7: 261-72$.

[15] Dehnad A, Shakouri H. A novel model of intelligent electrical load management by goal programming for smart houses, respecting consumer preferences. Energy Pow Eng 2013;5:622-7.

[16] Adika CO, Wang L. Smart charging and appliance scheduling approaches to demand side management. Int J Electr Pow Energy Syst 2014:57:232-40.

[17] Pedrasa M, Spooner T, MacGill I. Scheduling of demand side resources using binary particle swarm optimization. IEEE Trans Pow Syst 2009;24:1173-81.

[18] Conejo A, Morales J, Baringo L. Real-time demand response model. IEEE Trans Smart Grid 2010;1:236-42.

[19] Yu Z, Jia L, Murphy-Hoye M, Pratt A, Tong L. Modeling and stochastic control for home energy management. IEEE Trans Smart Grid 2013;4:2244-55. 
[20] Chen Z, Wu L, Fu Y. Real-time price-based demand response management for residential appliances via stochastic optimization and robust optimization. IEEE Trans Smart Grid 2012;3:1822-31.

[21] Shao S, Pipattanasomporn M, Rahman S. Grid integration of electric vehicles and demand response with customer choice. IEEE Trans Smart Grid 2012;3:543-50.

[22] Pomianowski M, Heiselberg P, Zhang Y. Review of thermal energy storage technologies based on PCM application in buildings. Energy Build 2013:67:56-69.

[23] Cabeza L, Castell A, Barreneche C, de Gracia A, Fernandez A. Materials used as PCM in thermal energy storage in buildings: a review. Renew Sustain Energy Rev 2011;15:1675-95.

[24] Oro E, de Gracia A, Castell A, Farid M, Cabeza L. Review on phase change materials (PCMs) for cold thermal energy storage applications. Appl Energy 2012;99:513-33.

[25] Zhou D, Zhao C, Tian Y. Review on thermal energy storage with phase change materials (PCMs) in building applications. Appl Energy 2012;92:593-605.

[26] Soares N, Costa J, Gaspar A, Santos P. Review of passive PCM latent heat thermal energy storage systems towards buildings energy efficiency. Energy Build 2013;59:82-103.

[27] Zhang M, Medina MA, King JB. Development of a thermally enhanced frame wall with phase-change materials for on-peak air conditioning demand reduction and energy savings in residential buildings. Int J Energy Res 2005;29:795-809.

[28] Chen C, Guo H, Liu Y, Yue H, Wang C. A new kind of phase change material (PCM) for energy-storing wallboard. Energy Build 2008;40:882-90.

[29] Diaconu BM, Cruceru M. Novel concept of composite phase change material wall system for year-round thermal energy savings. Energy Build 2010;42:1759-72.

[30] Chan A. Energy and environmental performance of building faades integrated with phase change material in subtropical Hong Kong. Energy Build 2011;43:2947-55.

[31] Kheradmand M, Azenha M, de Aguiar JL, Krakowiak KJ. Thermal behavior of cement based plastering mortar containing hybrid microencapsulated phase change materials. Energy Build 2014;84:526-36.

[32] Kheradmand M, de Aguiar J, Azenha M. Estimation of the specific enthalpytemperature functions for plastering mortars containing hybrid mixes of phase change materials. Int J Energy Environ Eng 2014;5.

[33] Lucas S, Ferreira V, de Aguiar JB. Latent heat storage in PCM containing mortars-study of microstructural modifications. Energy Build 2013;66: 724-31.

[34] Cunha S, Aguiar J, Ferreira V, Tadeu A. Mortars based in different binders with incorporation of phase-change materials: physical and mechanical properties. Eur J Environ Civ Eng 2015;19:1216-33.

[35] Kheradmand M, Azenha M, de Aguiar J, C-GJP. Experimental and numerical studies of hybrid PCM embedded in plastering mortar for enhanced thermal behaviour of buildings. Energy, 2015.
[36] Thermal insulation with extruded polystyrene fibranxps, 2011. <http:// www.fibran.com/frontend/index.php>.

[37] Vicente R, Silva T. Brick masonry walls with PCM macrocapsules: an experimental approach. Appl Therm Eng 2014;67:24-34.

[38] Incropera FP. Fundamentals of heat and mass transfer. John Wiley \& Sons: 2006.

[39] Regulamento das caracteristicas de comportamento trmico dos edificios (rccte), 2006.

[40] Thermal environment standards for human occupancy. 55. Atlanta, GA; 2004

[41] Sa AV, Azenha M, de Sousa H, Samagaio A. Thermal enhancement of plastering mortars with phase change materials: experimental and numerical approach Energy Build 2012;49:16-27.

[42] Abdollahzadeh M, Esmaeilpour M. Enhancement of phase change materia (PCM) based latent heat storage system with nano fluid and wavy surface. Int Heat Mass Transfer 2015;80:376-85.

[43] AL-Saadi SN, Zhai ZJ. Modeling phase change materials embedded in building enclosure: a review. Renew Sustain Energy Rev 2013;21:659-73.

[44] Fluent. User's guide, release 14.5., 2014. <http://www.ansys.com/>.

[45] Numerical simulation of the structural behaviour of concrete since its early ages: [phd thesis], 2009. <http://www.civil.uminho.pt/mazenha/resume2.htm, university of porto>.

46] Wang Y-H, Yang Y-T. Three-dimensional transient cooling simulations of portable electronic device using PCM (phase change materials) in multi-fin heat sink. Energy 2011;36:5214-24.

[47] Albadi M, El-Saadany E. A summary of demand response in electricity markets Electr Pow Syst Res 2008;78:1989-96.

[48] Aalami H, Moghaddam MP, Yousefi G. Demand response modeling considering interruptible/curtailable loads and capacity market programs. Appl Energy 2010;87:243-50.

[49] The iberian electricity market - mibel, 2014. <http://www.mibel.com>.

[50] Kempton W, Tomic J. Vehicle-to-grid power fundamentals: calculating capacity and net revenue. J Pow Sour 2005;144:268-79.

51] Zhu N, Wang S, Ma Z, Sun Y. Energy performance and optimal control of airconditioned buildings with envelopes enhanced by phase change materials. Energy Convers Manage 2011;52:3197-205.

[52] Barzin R, Chen JJ, Young BR, Farid MM. Application of PCM energy storage in combination with night ventilation for space cooling. Appl Energy 2015;158:412-21.

[53] Barzin R, Chen JJ, Young BR, Farid MM. Application of PCM underfloor heating in combination with PCM wallboards for space heating using price based control system. Appl Energy 2015;148:39-48.

[54] Qureshi WA, Nair N-KC, Farid MM. Impact of energy storage in buildings on electricity demand side management. Energy Convers Manage 2011;52: 2110-20. 